University of Nebraska - Lincoln

DigitalCommons@University of Nebraska-Lincoln

2020

Incels, Compulsory Sexuality, and Fascist Masculinity

Casey Ryan Kelly

Chase Aunspach

Follow this and additional works at: https://digitalcommons.unl.edu/commstudiespapers

Part of the Critical and Cultural Studies Commons, Gender, Race, Sexuality, and Ethnicity in Communication Commons, and the Other Communication Commons

This Article is brought to you for free and open access by the Communication Studies, Department of at DigitalCommons@University of Nebraska - Lincoln. It has been accepted for inclusion in Papers in Communication Studies by an authorized administrator of DigitalCommons@University of Nebraska - Lincoln. 


\title{
Incels, Compulsory Sexuality, and Fascist Masculinity
}

\author{
Casey Ryan Kelly and Chase Aunspach
}

University of Nebraska-Lincoln

\begin{abstract}
Incel, the now-widely circulated portmanteau for involuntary celibacy, denotes a growing community of mostly cisgender men who are unable to find sexual partners or forge romantic relationships. Organizing in online networks, these men blame their exile from sexual relations on everything from feminism and sexual liberation to genetics and natural laws of attraction. In this essay, we offer an asexual critique of compulsory sexuality in online incel communities to illustrate how the sexual imperatives that animate fascism and the politics of the alt-right rest on myths of an insatiable male sex drive. We argue that incel discourse repurposes liberal conceptions of sexual liberation as well as alternative theories of intimacy crafted by queer and asexual communities to advance an abject and fascist form of masculinity. Rather than understand incels as sexually repressed and unable to assimilate hegemonic masculinity, we theorize incel discourse as a white militant extension of compulsory sexuality that transforms alternative intimacies into violent masculinist fantasies of invulnerability and the sexual will-to-power. Content warning: this essay examines potentially traumatizing discourses concerning sexual assault, racial violence, and discriminatory beliefs. Please read with caution.
\end{abstract}

Keywords: Compulsory sexuality, fascism, involuntary celibacy, male sex drive, white masculinity, white supremacy

In Judd Apatow's 2005 film The 40-Year-Old Virgin, the protagonist Andy is a mild-mannered celibate who, with the help of his sexobsessed coworkers, is finally able to leave behind his sexually repressed and emotionally stunted world of video games and collectable

Published in Feminist Formations, Vol. 32 No. 3 (Winter) pp. 145-172.

doi:10.1353/ff.2020.0044

Copyright (C2020 Feminist Formations. Published by Johns Hopkins University Press. Used by permission. 
action figures for the adult world of dating, marriage, and, eventually, sex (Apatow 2005). The lighthearted romantic comedy featured divergent representations of what Casey Ryan Kelly has called the man-boy, a persona "obsessed with some combination of play, selfinterest, homosocial bonding, and serial dating" who "repudiates traditional breadwinner masculinity by extending the youthful pleasures of adolescence into adulthood" (Kelly 2016, 60). The 40-Year-Old Virgin negotiated the tensions of a cultural moment in the United States in which abstinence-until-marriage and family values were national policy and yet sex and serial dating remained consummate performances of hegemonic masculinity. At approximately the same time, the Twilight Saga (2008-2012) celebrated a more monstrous and malevolent virgin (Hardwick 2008). Edward Cullen's tumultuous pursuit of neotraditional romance was constantly imperiled by his vampiric thirst-a thinly veiled metaphor for frenzied sexual desire. Both Andy and Edward suffered a forced exile from the culture of sex and dating-an exile made more painful by their innate sexual desires. Both films illustrate an ambivalence nestled within national (hetero)sexual culture between morality and the male sex drive. Moreover, both characters evince a representational association between whiteness and virginity that underwrites ideologies of sexual purity. Both represent a return to the traditional courtship rituals and family values long-valorized within white heterosexual culture. Indeed, Edward is not only white, but his skin sparkles in the sunlight.

We begin this essay with a discussion of these films as representative anecdotes for how normative sexual culture presupposes the existence of an innate male sex drive that must be channeled into sex and normative relationships lest it lead cisgender white men to ruin. We also wish to foreground the racial and gender investments in the public discourses of sexual morality and desire. Both films also intimate a seething and quiet rage festering in the dark recesses of marginalized white male subcultures-a loose collective of alienated young cisgender men who might identify with Andy and Edward's struggles with virginity yet perceive themselves as incapable of changing their fate. A decade later, the public would be made aware of a vast network of disaffected young men whose struggles with dating, sex, and relationships would incite a nihilistic, misogynistic, and violent discourse about their involuntary celibacy. The now-widely circulated 
portmanteau incel refers to people who are unable to find heterosexual sexual partners and forge romantic relationships. Organizing across online networks, these individuals blame their exile from sexual relations on everything from feminism and sexual liberation to genetics and natural laws of attraction.

But unlike Andy and Edward, many incels find neither relief nor relational fulfillment. Tragically, incels have gained national attention through a series of mass shootings and sprees of violence. In 2014, University of California, Santa Barbara college student Elliot Rodger murdered seven and injured fourteen people before taking his own life. Prior to his murderous rampage, Rodger uploaded a manifesto "My Twisted World" and a video to YouTube entitled "Elliot Rodger's Retribution," in which he sketched his plan to punish women who spurned his sexual advances. In a Facebook post prior to a 2018 murderous rampage in Toronto, Alek Minassian cited Rodger as a source of inspiration: "The Incel Rebellion has already begun! We will overthrow all the Chads and Stacys! All hail the Supreme Gentleman Elliot Rodger!" ("Toronto Van Attack Suspect Praised 'Incel' Killer" 2018). ${ }^{1}$

In January 2019, Christopher Cleary was arrested for posting that he was "planning on shooting up a public place soon and being the next mass shooter cause ready to die and all the girls turned me down is going to make it right by killing as many girls as I see" (Bever 2019). Although not all incels endorse violence, the incel forums where these individuals were radicalized remain populated with virulent misogyny, rape fantasies, self-loathing, and general despair. It is difficult to estimate the exact racial demographics of participants, but scholars who have studied these sites have found many instances of anti-Black racism, anti-Semitism, and Islamophobia, along with comments endorsing eugenics and scientific racism (Jaki et al. 2019). Heidi Beirich of the Southern Poverty Law Center estimates that incels are largely "young, frustrated white males in their late teens into their early twenties who are having a hard time adjusting to adulthood. They're the

1. By Chads and Stacys, Minassian was referring to an incel caricature of attractive and popular people who have no trouble finding sexual partners. 
same kinds of people you find in white supremacy writ large.. They have grievances about the world they've placed onto women and black people" (quoted in Collins and Zadrozny 2018). In 2017, the website reddit.com removed the $\mathrm{r}$ /incel portal (which had approximately 40,000 members) because its content violated the site's updated policy against advocating violence (Solon 2017). Yet countless other forums and blogs, such as incels.co and love-shy.com, are still in operationamplifying the voice of a troubling subculture within the national dialogue about sex.

Incel websites have become important nodes in a vast virtual network of men's rights discourse that has radicalized and recruited young men into the contemporary alt-right subculture (Kelly 2020) The so-called manosphere is a vast network comprised of incels, pickup artists, fathers' rights activists, anti-feminists, and male separatists, among others (Nagle 2017). Although their agendas diverge, they share the common mythology of the Red Pill-an internet-born concept of masculinity premised on the belief that men have been subjugated by feminist programming and must awaken to this grim reality before they can turn the tables on women in dating, sexual relationships, and career success (Bratich and Banet-Weiser 2019). The men's rights network also cross-pollinates with other far-right and white supremacist networks, rapidly circulating violent racist misogyny and directing traffic toward neofascist groups (Futrelle 2017; Woods and Hahner 2019). Gender Studies scholars have argued that the reactionary politics of the alt-right are organized around the reinstatement of white masculine dominance and the subjugation of women and people of color (Banet-Weiser and Miltner 2016; Ging 2019). According to scholars at the Anti-Defamation League's Center on Extremism, incel websites illustrate a "robust symbiosis between misogyny and white supremacy" insofar as their overlapping networks that cultivate anonymous misogyny act as a bridge between related forms of hatred. In this regard, incel websites are also a conduit to white supremacy and neofascism. Indeed, fascist movements have long been preoccupied with men's virility, homosociality, traditional gender roles, and invulnerability to women along with white supremacy (Bellassai 2005; Spackman 1996). We contend that even as incels refuse or fail to embody the masculine ethos of fascism, their discourse supports and reflects an underlying adherence to the racial and sexual imperatives 
that animate far-right movements. That is to say that incels devote significant attention to the hypersexuality and biological inferiority of nonwhite people while demanding that sex, coupling, and reproduction be dictated by the state to ensure proper sexual and racial order. These sexual and racial imperatives are not only drawn from Umberto Eco's ideology of ur-fascism, which preaches men's sexual will-to-power, ${ }^{2}$ but also from the liberal orthodoxy of a sexual culture that is organized around the mythologies of the male sex drive (Eco 1995): incels suffer not from sexual repression but the liberationist imperative that one must talk about, pursue, and enjoy sexual activity in the name of social cohesion and racial domination.

We contend that incel discourse, along with the politics of the altright, are a logical extension of the demands of compulsory sexuality-a culture that cannot comprehend intimacy without sex, identity delinked from sexuality, or white masculinity absent an aggressive and fulfilled sex drive. At the same time, compulsory sexuality is a shifting terrain insofar as it can be leveraged both as the sociobiological imperative of white masculinity and as a racist point of contrast between the ostensibly civilized white subject and the hypersexualized Black subject. Thus, incel discourse idealizes sex as a tool of racial domination by drawing from the historical articulations of asexuality and whiteness and hypersexuality and Blackness. Ianna Hawkins Owen $(2014 ; 2018)$ argues that asexuality is treated both as a virtue of self-mastery or innocent purity when practiced by whites and, at the same time, a proscription for the sexual domestication of Black subjects. White masculine hegemony, then, is buttressed by the notion that white men are sexually superior and thus are in the best position to define the parameters of appropriate (a)sexuality. Such parameters always position white sexual restraint as evidence of racial superiority. Indeed, involuntary celibacy operates differently for Black men and men of color than for white men, because asexuality has been consistently misapplied by white people as a symbolic form of pacification and domination (Gupta 2015). Hence, incel discourse in the contemporary manosphere draws from the logics of sexual and racial superiority, of whiteness and white supremacy, to legitimize fascist demands.

2. This phrase is a reference to Friedrich Nietzsche's discussion of ultimate human drives. 
Unfortunately, the popular response to incels does little to question the intersections of white supremacy and compulsory sexuality. Indeed, one common facetious response to incels has been to suggest that if only we can find them girlfriends, the problem would go away. Here, sex not only creates but saves lives. But as recent scholarly explorations of asexuality have illustrated, such flippant responses illustrate how sexuality is fundamentally compulsory. Where sex is imagined to be the innermost expression of personhood, the key to mental and physical health, and the underwriting source of personal fulfillment, sex is constructed as a biological and cultural imperative. Compulsory sexuality, in Gayle Rubin's words, is "the idea that sex is a natural force that exists prior to social life" (1975, 275). Moreover, compulsory sexuality is advanced by the notion that the male sex drive is a necessary and lifesaving imperative. Wendy Hollway argues that compulsory sexuality presupposes that men's desires are "directly produced by a biological drive, the function of which is to ensure reproduction of the species" (1998, 231). Ela Przybylo adds that "the male sexual drive discourse is thus entangled in a biological imperative according to which sex is formulated as a natural impulse or drive, on par with eating and sleeping, and as unmodulated by cultural and relational contexts" $(2014,232)$. And while it takes aim at limitations of the sexusociety - "the diluted omnipresence of sexuality in our western contemporary present"-we contend that incel discourse ultimately reaffirms the masculine imperatives that underwrite compulsory sexuality (Przybylo 2011, 446). Incels incite the very sexual discourse they despise, and in doing so craft a vengeful fascist masculinity premised on homosocial commiseration, invulnerability to women, white supremacy, and a shared preoccupation with satisfying the male sex drive.

In this essay, we offer an asexual critique of compulsory sexuality in online incel communities to illustrate how the sexual imperatives that animate the alt-right are nestled within seemingly progressive and liberationist edicts on compulsory sexuality. To this end, we contend that incel discourse contributes to the neofascist and white supremacist ideologies of the alt-right by naturalizing the male sex drive as a self-valorization of white identity, self-mastery, and entitlement while casting Black men and men of color as a sexual threat. We add that incel discourse repurposes liberal conceptions of sexual 
liberation as well as alternative theories of intimacy crafted by queer and asexual communities to construct incels as a sexually and racially aggrieved community. Rather than understand incels as sexually repressed and unable to assimilate hegemonic masculinity, we theorize incel discourse as a militant extension of compulsory sexuality that transforms the paradigm of sexual liberation into the violent masculinist and racist fantasies of the sexual will-to-power. And though it seems to pain its users, incel websites present readers with an incessant stream of agonizing sexual discourse-a seemingly endless number of threads on sexual desire and failure, rape fantasies, evolutionary pseudoscience, theories on women's psychology, cries for help, and demands for power over women. However, as Michel Foucault illustrated, the dialectics of repression versus liberation misreads the operations of power as centrally located in forms of subjugation, censorship, and dominance (1978). Thus, it is the proliferation of sex talk and not its prohibition that opens up the body and sexuality to new regimes of control. In this regard, incel discourse contradicts an important point made emphatically within the scholarship on asexuality: that it is the sexual imperative that occludes other modes of fulfillment and healthy intimacy.

This essay unfolds in three sections. First, we explain the historical development of the term incel alongside its eventual cooptation by participants of the manosphere in crafting diffuse and reactionary forms of masculinity that we characterize as the queer unmaking of asexuality. Next, we analyze the themes that trace throughout incel websites, noting how incel discourse paradoxically reifies compulsory sexuality and male sex drive discourse. Finally, we turn to the Elliot Rodger's manifesto to show how incel discourse makes the leap from word to deed and consummates fascist fantasies of male dominance. We conclude that the nihilistic, misogynistic, and sometimes violent discourse that populates incel networks speaks to how the sexusociety has narrowed the range of masculinity, intimacy, eroticism, desire, and fulfillment to penetrative heterosexual sex acts. To be sure, there are other ways of conceptualizing erotics beyond the boundaries of sex. As Audre Lorde explains, erotics can mean "the sharing of joy, whether physical, emotional, psychic, or intellectual” (1984, 56). Thus, we surmise that the cooptation of asexuality by the far-right negates the radical queer potentials of nonsexual and asexual erotics 


\section{Fascist Masculinity and Compulsory Sexuality}

Hegemonic masculinity denotes the taken-for-granted attributes, behaviors, and performances that comprise what it means to be a man at a particular time and place (Berger, Wallis, and Watson 1995; Carroll 2011; Connell 2005; Gardiner 2013; Kimmel 2012). Although masculinity is historically contingent and sometimes fluid, hegemonic designates the predominate ideological and aesthetic templates through which masculine subjects are made legible, particularly when deployed as a discursive mechanism to discipline, police, and judge subjects against normative conventions. Despite its historical transformations and variations across cultures and subcultures, hegemonic masculinity is most readily identifiable in white, cisgender, and heterosexual bodies, defined by attributes such as toughness, self-reliance, individualism, muscularity, rationality, dominance, competitiveness, and sexual prowess, among others (Bederman 2008).

Recently, some masculinity studies scholars have observed that although conforming to hegemonic masculinity unlocks social capital and material privileges, masculinity also operates under more abject and transgressive registers (Johnson 2017; Kelly 2018; King 2011). Adopting the term abject hegemony, Claire Sisco King argues that white masculinity "prevails not by expelling that which is Other, but by sacrificing its own fictions in order to absorb, assimilate, and make room for Otherness, offering up, for instance, cherished narratives of masculine strength, aggression, and invulnerability in order to indulge in femininity, passivity, and lack" (2009, 371). King's theory of abject hegemony instructs us to consider how incels' confessed inability to conform to hegemonic masculinity can be understood as part of the absorbent and adaptive character of masculinity. Hence, we read incel discourse from within the logics of abject hegemony whereby the transgression of masculine norms, including expressions of weakness and sexual ineptitude, represents an extension of masculine power. In other words, incel discourse illustrates how abject hegemony is enacted through appropriations of femininity so that masculinity can become more diffuse, amalgamated, and less able to be pinned down. The so-called crisis in masculinity, then, is a call to arms that radicalizes young men and makes room for so-called geeks to also take part and invest in masculinity-albeit in an opaque form (Robinson 2000). 
For this reason, their investments in compulsory sexuality, the myth of the male sex drive, and women's subjugation all belie incel claims of victimhood.

We advance an asexual critique of incel discourse to illustrate how strategic failures of masculinity are in fact essential counterparts to masculine domination. To wit, our analysis evinces how incel discourse figures into the alt-right's rhetoric and politics. Indeed, fascist iterations of masculinity make room for disparate groups of men to coalesce around the will-to-power and the return of hierarchy, order, and authority. As Barbara Spackman observes, fascism promises men both independence from and invulnerability to women through the solidification of homosocial bonds (1996). Fascism historically entails the scapegoating of racial minorities for social problems and the construction of a mythic white or Aryan identity whose recovery delivers to its adherents a sense of superiority and separateness from racial outsiders. For instance, the contemporary alt-right advocates for ethnonationalism, or a white state and homeland, and proposes that its members fan the flames of racial resentment to accelerate unrest and violence in order to bring about white authoritarian rule. Incel men also play their part in this process by forming their collective identity through pain and fantasies of violent retribution against threatening caricatures of women, Black men, and other men of color. As Todd McGowan argues, fascism is structured around paranoid fantasies of expelling an enjoying other or an internal enemy who "enjoys illicitly at the expense of the social body as a whole" (2013, 118-19). Fascism offers to purify the social order and pave the way for the return of stability and traditional social arrangements grounded in white supremacy (46). Incel masculinity aligns itself with the imperatives of fascism in its conjectures about inexorable genetic hierarchies, the cunningness of women and men of color, and the return of social arrangements that guarantee white men's power and sexual fulfillment. Characterizing themselves as victims, incels also reframe weakness and passivity as justifications for militancy and violence against women. Whereas other scholars have rightfully identified how toxic masculinity fuels the alt-right, our analysis demonstrates how compulsory sexuality underwrites the efficacy of fascist politics and white supremacy. 


\section{An Asexual Critique of Incel Discourse}

Before turning to our critique of incel discourse, it is important to consider how the concept of involuntary celibacy has been appropriated from queer and asexual communities and folded into the compulsory sexuality of the alt-right. Up to this point, we have theorized the masculine entailments of contemporary incel discourse; however, the development of incel discourse and personas is not and has never been stable. We argue that refrain is a key rhythm in how incel has blossomed as an identity and community. It is worthwhile to brush off the term and community's queer roots to play with the minor potentialities now quieted by most incel spaces. By enunciating these linkages, we aim to open up new futures both for asexual orientations to queer theory and for queer fissures within incel discourse to destabilize its problematic logics and violence.

To conflate incel and asexuality is dangerous and ignores the degree to which incel discourse is coherent with the male sex drive and sexual imperative myths. We thus offer in the remainder of this essay a critique of incel discourse from the theoretical vantage point of asexuality. In what follows, we treat incels as cultural figures constructed and identified within the public imaginary, primarily through collective participation in online forums. Although there are flesh-and-blood individuals who experience pain and social isolation, our critiques are not directed at persons but personas invented through discourse.

As such, we analyze texts posted on publicly searchable websites like blogs and forums-without participation in these communities or interaction with members-in a practice of humanistic criticism that is not human subject research as defined by the 2018 revisions to the U.S. Common Rule (Cornell Law School, n.d.). We have made a series of what the Association of Internet Researchers' "Internet Research: Ethical Guidelines 3.0" names judgment calls regarding how to care for users' posts in this analysis, understanding that "ambiguity, uncertainty, and disagreement are inevitable" when selecting, critiquing, and circulating online discourse through publication (franzke et al. 2020, 6). In what follows, we attribute writings to their authors, be that with the full names or usernames associated with each post. Like most online forums, users on the Asexual Visibility and Education Network (AVEN) and incels.co create pseudonymous usernames and are careful not to share identifiable information for fear of being 
doxxed. Our practice of picking representative anecdotes and texts mirrors the expectations for publicity and privacy of the communities from which they originated. When we use direct quotes, we keep the spelling and grammar the same as it appears online.

\section{Appropriation: From Alana to Elliot Rodger}

We associate incels with toxicity and misogyny, but the term was actually coined by a Canadian woman named Alana in the late 1990s. In an article on her personal website, Alana described her motivations to give language to being involuntarily celibate: "People can help each other accept themselves and solve any problems they might have. Each person who speaks up makes it easier for others to "come out of the closet.' . . . So I am speaking up about being involuntarily celibate" (Alana 1997a). Alana openly identified her notion of being involuntarily celibate as coming from a lesbian-feminist perspective-a stark contrast from the intensified heterosexism of the language of the male sex drive. Alana wrote that she did not have a girlfriend until she was 24, and about how grappling with her sexuality delayed her placement on a normative, romantic life course-what Jack Halberstam might call queer time, describing "how respectability, and notions of the normal on which it depends, may be upheld by a middle-class logic of reproductive temporality" $(2005,4)$. Originally conceived, incel was a recovery of queer identity from the presumed trajectory and normative pacing of (hetero)sexual development.

After her first relationship dissolved, Alana believed the source of her involuntary celibacy to be mostly personal blockages to relationships, a position obviously differing from our emphasis on the force of compulsory sexuality. Alana turned to self-help books about intimacy, therapy, dermatology, and even Naomi Wolf's 1990 The Beauty Myth to improve her self-esteem and make dating easier in the future. Inviting others to join her journey, she described her transformation on her website:

My greatest struggle has been to learn to tell the truth about what I see, and how I feel. I could not start dating until I could tell myself the truth: that I wanted a partner, and that I was a likeable, attractive person. Then I had to take risks and tell other people the truth: I felt attracted to them. Now that I can recognize and tell people my feelings, I have much more control over my life and my future (Alana 1997a.). 
To share these insights and offer support to others experiencing involuntary celibacy, Alana created the aptly named Alana's Involuntary Celibacy Project. Hosted on her personal website, the Involuntary Celibacy Project coupled itself with a private email list that went public in 1999 (Alana 1999). Alana encouraged people to share their stories, which included themes of shy personalities; new life circumstances that made meeting people difficult; negative self-perceptions; and many changes people made like losing weight, spending time on themselves, and engaging communal life by joining a choir and interest groups. There were no pressures to categorize who was and was not a real incel. Reading Alana's anonymous summaries of members' journeys to the term involuntary celibate, we hear resonances with interviews on asexual experiences (Alana 1997b), like having a "background that is less open about sex than [a] person's adopted country" and explaining to "others they are uninterested in relationships, marriage, children and prefer to focus on their career, but they know they are lonely without a partner." Incel, at this juncture, functioned as an invitational identity for people with otherwise nonnormative sexual experiences (without questioning the pressures to be sexual that they felt in the first place).

Alana's Involuntary Celibacy Project and its feminist approach migrated in the early 2ooos, first merging with another forum to create IncelSite.com in 2004. The community moved again in 2006 to a new (but now deleted) forum titled IncelSupport, and community norms continued to emphasize internal improvement to overcome feelings of inadequacy. In an episode of the Reply All podcast, host PJ Vogt recalled what he learned from an IncelSupport moderator after Alana stepped away from incel culture: "The community tried to police itself as if she [Alana] were still there, which meant if new members showed up who were blaming women for their problems or espousing misogynist ideas, the community would try and respond"; at the same time, other incel spaces began forming, the most notable of them called love-shy.com (Vogt 2018). Under the guise of free speech, love-shy.com became a hotbed of misogyny and flirtations with gender-based violence and murder. A move of externalization, love-shy .com framed the causes of involuntary celibacy away from the self and toward women, political correctness, feminism, and liberalism. 
Marjan Siklic, an incel blogger and forum poster from Croatia, exemplifies how incel was later transformed into its most intensified and fascist forms. Before we move forward, we want to reiterate a content warning to readers: the following material contains graphic references to sexual violence, misogyny, and racism. Labeled a lolcow (a person who can be exploited for laughs) by the wider incel community, Siklic was known for his extremism and advocacy for governmental solutions to inceldom. We dwell with his rhetoric not necessarily for its representativeness of all incels but because in his radicalism, he revealed the otherwise quiet parts of incel thinking and fantasy play out loud. Siklic's most notable policy suggestion was for governments to pay women to go on up to thirty dates with incels. Governments, per his proposal, would give men opportunities to practice dating skills while showing women, whose ideas of attraction have been corrupted by feminism, that these underappreciated men are morally and biologically superior to the alpha males (or Chads) they chase (Siklic 2013a); these dates, Siklic maintained, would serve society as a whole and address the sincere pain many incels face since the inability to fulfill their sexual needs drives some men to suicide (2013b).

Siklic also supported a return to patriarchy through "the inevitable massacre of liberals by Muslims they worshiped like gods" (2013b). According to him, women in Europe and the United States "want no consent, respect, or any basic consideration. To them, men who show even the slightest hint of intelligence and morality are utter scum. They want to be crushed like old beer cans" (2013b). By contrast, Siklic lauded Muslim women who, in his mind, forced by men to live a life of subordination and chastity, do not buy into this Stacy/Chad logic. He thus applauded the migration of Muslim immigrants to Europe, "luckily brought here to fertilize Western women" (2013a). In contrast to the white nationalism and Eurocentrism of many alt-right and alt-right-adjacent groups, Siklic painted a vision of Europe as majority-Muslim and potentially thriving under Islamic law, one in which all men-not just the most attractive or successful-would once again be able "to do what they want with women and colonize them with pregnancies. Islam can create the conditions to return to patriarchal, religious societies where men and women can flourish in a biologically divined asymmetrical relationship. Women once again take care 
of children, remain virginal, and are dependent on their husbands for sustenance" (Siklic 2013a).

We want to take a moment and work through Siklic's rhetoric. The fantasy of Europe being colonialized by Muslim men is a return to a European history otherwise scrubbed from public memory-Islam's influence on the development of Western culture. Underwriting an externalization discourse like Siklic's is a set of anti-feminist assumptions that weave together shoddy, cherry-picked research studies and evolution-inspired cultural theories and histories. Although we cannot detail every theory here, putting some of these ideas in conversation with fascism helps highlight how Siklic (and later Elliot Rodger) can stand in for larger incel culture. Incels work from the assumption that feminism is a cultural insurgence and sexual strategy that has fundamentally altered gender and sexuality to benefit women and hurt men. As described by Imran Khan in "The Misandry Bubble," a key text in anti-feminist, masculinist communities:

The Western World has quietly become a civilization that undervalues men and overvalues women, where the state forcibly transfers resources from men to women creating various perverse incentives for otherwise good women to conduct great evil against men and children, and where male nature is vilified but female nature is celebrated. This is unfair to both genders, and is a recipe for a rapid civilizational decline and displacement (Khan 2010).

Note how women, in making most men desperate for their sex and to procreate, hold all of the power in this worldview. Due to the scarcity of affection, men are willing to settle for women below their reciprocal level of attractiveness, breaking the evolutionary order that men and women only pair to create the strongest offspring. This passage exemplifies how this form of eugenics fuses scientific racism with ableism to naturalize sexual and racial hierarchies.

In her essay "Fascinating Fascism," Susan Sontag notes that fascists, ever keyed into the theatricality and aesthetics of political life, stage outlandish images of the sexuality of the past "because it is those images (rather than memories) from which they hope a reserve of sexual energy can be tapped" (2002, 104). Like other fascist movements, the alt-right insists that this disruption is only furthered as Western culture and legal systems, imbued with liberalism, allow women more agency to file for divorce and dispossess men of 
their children and wealth. Seemingly victimized by an unjust system that goes against the natural laws of society, incels and fascists alike rebuke what they see as a dead end for themselves and societies: absent the cultural mechanisms of patriarchy, there is no glue to keep men happy and families together throughout the life course, necessitating swift action and the use of violence to correct for the pain distributed unevenly onto men and children.

Indeed, families are key locations of identity production for fascism. Wilhelm Reich wrote in The Mass Psychology of Fascism that families are miniature authoritarian states that socialize children into subservient positionalities. Working in tandem with churches, fascism creates political and imaginative docility by denaturalizing sex from a young age and "inhibiting sexual curiosity and sexual thinking in the child, a general inhibition of thinking and of critical faculties" ([1933] 1980, 25). In addition to fostering docility, family structures are tied to the means of production. The Nazi shibboleth blut und boden (blood and soil) can be seen as connoting how important procreation and robust families were to enacting a vision of Germany reliant upon agricultural success. Incels' sexuality follows along in a similar, repetitive riff. In promoting a return to Islam and constructing men and women as prehistorical, strictly biological beings, Siklic slips from sexual frustration into fascism through aggrieved entitlement-the "sense that those benefits to which you believed yourself entitled have been snatched away from you by unseen [read: feminist] forces larger and more powerful" (Kimmel 2015, 18). Inverting this logic, it is also clear how compulsory sexuality unlocks critiques of the alt-right that add intersectional texture to its toxic masculinity and whiteness.

Fascists and alt-right-minded incels idealize women's fertility as a political imperative while also fetishizing a homosocial fantasy of male autarky in which men are both invulnerable to and independent of women. As Daniel Woodley argues, "fascist propaganda is replete with references to virility, fertility, male invulnerability and superhuman power, suggesting an asymmetric differentiation between a masculine 'totality' and a feminine 'lack' " (2009, 218). Spackman adds that beyond its biological imperatives, fascism is also a male event in which a homoerotic charge promotes a "cognitive and ideological apartheid around homosexuality" (1996, 51). Both incel and fascist 
discourse converge on a dystopian sense of homosocial world-making in which the bonds of the polity are homosocial, yet homosexual desire must be sublimated in the interest of a virtuous masculinity capable of biological reproduction.

\section{Black Pilled: Incels and the Sexual Imperative}

As the manosphere seized the politics of asexuality, incel transformed from queer indictment to cishetero valorization of compulsory sexuality. Soon after Minassian's murderous rampage in Toronto in 2018, members of the AVEN forum expressed concern that an unknowing public might confuse those who identify as asexual with incels. In a post entitled "Concern for the Rise of Incel," one member wrote:

The way I see it, visibility of asexuals is already tough enough. But if the idea of "this group = no sex" becomes more attributed to Incel (since they make the news more and more), I do wonder if we won't be automatically dragged into their circle whenever the public sees, thinks or talks about asexuality. And what that might mean for our goals to be more visible and accepted. I know, I know. We are nothing alike and not being able to have sex despite wanting it is not the same as having no sexual attraction / desire. But given how it is already difficult enough to get people to understand asexuality, I have to admit I don't fully trust the public to now start to discern the very big difference between the two. Am I alone in this? Has no one else shared this worry? (umbasa 2018).

Others participating in the thread were rightly concerned that it would be inaccurate at best and dangerous at worst to compress incels and asexuals into the same category, or to attempt to make sense of each by refracting them through the universalizing lens of sexual repression. Whereas asexual denotes a person who does not experience feelings of sexual attraction, incel marks those harboring sexual desire who believe they have been exiled from sexual intimacy. One group is a sexual orientation and characterized by a proud approach to low levels of sexual attraction; the other is dangerously preoccupied with sex and with its absence in their lives. Given this radical divergence, how could one confuse a disposition of no sexual attraction with one of sexual entitlement and frustration? As Przybylo clarifies, where asexual individuals may have sex but not necessarily feel sexual attraction 
or mourn the loss of sexual desire, involuntary celibacy "suggests the reverse-that if one is not provided sex or is denied sex, one is incomplete, unfulfilled, and lacking” (2019, 138). Note, too, that whereas incels tend to veer toward the far right in their politics, most asexual people do not share this political affinity or group leaning. Also, asexual people are comprised of many genders, including many women and agender, genderqueer, nonbinary people (Scherrer 2008).

To be clear, asexuality and involuntary celibacy share little (if anything) in common as dispositions toward sex and sexuality. As we argued in the previous section, prior to its present usage, incel was ostensibly hijacked by misogynistic men looking to explain their feelings of frustration and victimhood. Hence, at a closer glance, there are many ways in which contemporary incels uphold and even naturalize many of the tenets of the sexusociety. In one sense, the conflation of asexual and incel is only possible in a culture organized around compulsory sex and sexuality and its attendant biological (Seidman 1992), orgasmic (Potts 2016), and coital (Nicolson 1993) imperatives. Asexual and incel dispositions both lie outside the sexusociety's grid of intelligibility, its cartography of "obsessive repetition of sexual deeds, desires, thoughts which fuels further repetition and thus acts coercively and in favour of certain deeds at the expense of others" (Przybylo 2011, 448). Particularly where masculinity is concerned, at first glance, withdrawal versus exile are conflated as fundamentally the same inasmuch as both fail to uphold, valorize, and perform forms of manliness organized around both having sex and demonstrating an excessive interest in sex. As neither disposition fits with the cultural scripts of manhood, both can be dismissed as incomprehensible without, in anyway, impugning the contradictions, impossible demands, and exclusionary impulses of the sexusociety.

But important differences bear themselves out when analyzed through the lens of asexual theory. First, incel discourse decries the addled and painfully aroused body of the sexusociety yet finds no alternative to the biological imperative. For instance, a large group of incels in online forums subscribe to the vernacular black pill theory, which is the belief that genetic laws of attraction-knowledge of which is putatively derived from evolutionary psychology-dictate that men with undesirable traits are unlikely to find mates, and that women are hardwired to seek out a small percentage of alpha men with particular 
physical attributes, including ideal weight, height, musculature, facial structure, race, and ability. Referenced frequently by the slogan "It's over," the black pill theory states that self-improvement and refining one's dating game can do next to nothing against the inexorable laws of human nature. Incels are, therefore, inevitably exiled from sex and relationships. According to one poster on incels.co:

This is what the blackpill is really about: the truth, supported by facts. When studies and data like this exist, it is impossible to swallow bluepilled ideologies such as "just put yourself out there" and "just be confident" when there are many inherent things about a man that can make him objectively undesirable in the sexual market (blickpall 2018).

Participants on incels.co, incels.net, and similar sites search through peer-reviewed scientific journals to find empirical evidence for the fact that sex is governed solely by biological and genetic factors that are beyond cultural explanation. In this way, incel black pill theory affirms the tenets of compulsory sexuality. Sex, incels argue, is governed by iron laws in which all men are driven by reproductive instincts, yet only a small percentage of them are able to find sexual partners with great ease. Incel discourse, in all its overwrought agony, is an extension of a culture that can neither imagine sex as product of culture nor masculinity absent an active and fulfilled sex drive. Incel discourse becomes yet another mechanism that advances the mythologies of the male sex drive by treating the drives as apolitical and ahistorical (Marcuse 1974). According to the Incel Wiki, "the information here is not a matter of 'opinion' or 'belief' but rather proven scientific fact. It is not meant to push any particular social or political agenda, but rather to educate about human nature without bias" ("Scientific Blackpill," n.d.). Even in their opposition to the sexusociety, some incels simply reaffirm its basic foundations.

Second, incel discourse participates in the regulation and narrowing of intimacy and personal fulfillment to penetrative heterosexual sex. Though not exclusively, many users on incel forums are preoccupied with innate biological needs, genetic determinism, and feminism's unnatural repression of cisgender men's needs. Users find that romantic relationships are important but they must ultimately be predicated on the fulfillment of base natural desires. And although hegemonic masculinity is underwritten by sexual ability and performance, it is 
the expression of innate sexual appetites and sexual preoccupation in general that are the easiest and most socially acceptable ways to convey the male sex drive to others. Hence, sex talk, not simple participation in similar sex acts, is the primary mechanism by which men are encouraged to establish homosocial relationships with other men. Even in the case of incels, where sex talk is often an expression of ineptitude or tragedy, sex nonetheless remains central to self-actualization, maturation, and development of romantic relationships. In one sense, incel forum discussions about sexual desire tend to concentrate on how innate biological drives are repressed by a feminized state apparatus. For example, in a thread titled "Are Incels All About Sex or [Do] They Want Love?," one forum member argued the following:

Throughout the history of mankind men have always being the ones that care excessively about looks, as we are more prone to sexualised the female body and it is more instinctual to us to care about looks that any other factor as we are more prone to seek sex.... [W] hen it comes to sex, having preferences over good body types are natural, instinctual (Retrycon 2019).

In this passage, the author conflates nature and culture in assuming that sexual desire and the practice of sexualizing women are a reflection of instincts rather than a social construction of sex and gender. Participants debate how and in what ways-rather than whether or not-society mirrors nature and biology. For instance, Saint Escortcel (2019), another user on the thread excerpted above, added, "Its biological and brought about by society mostly society sucks its adverts and consumer culture that makes girls and boys into brainwashed sheep so they don't know what they want." This response understands the relationship between nature, culture, and desire as a circuit in which biological instincts produce social relations, and that culture and advertising merely reinforce this relationship.

Ultimately, users evade responsibility for their problems by appealing to what they believe to be immutable laws of nature. Yet at the same time, they express the belief that society should reflect natural rules insofar as its purpose is to fulfill biological needs. For instance, one user argued, "We want our biological needs satisfied by society, just as they allow us to satisfy all of our other needs. This is not an unreasonable demand because society would not exist without 
men" (DisabledFace 2019). Here, we see the influence of eugenics to the extent that society should mirror nature even as the user blames nature for their pain.

But also note the influence of eugenics reflected not only in the content but also in the choice of the username itself. Incel forums are replete with self-deprecating and abject names that point to an assumed relationship between, nature, sexuality, and able-bodiedness. In a more crass post, a user named lordoftheincels puts it as such: "Mother Nature is not allowed in society, not allowed to have a giant erect dick that satisfies a woman's thirsty needs" (2019a). These representative threads outline a clear and immutable set of biological needs that underwrite everything from romantic relationships to the social contract. Users tend to blame women's equality and feminism for disrupting a natural order and crafting a system of government predicated on satisfying the biological and genetic imperatives of the few. At the same time, this claim is in tension with the belief that nature is also the root cause of their woes.

Third, although it is important to acknowledge the lived pain expressed by young men facing social isolation, the representation of sex and sexuality emerging from these forums reifies the biological, orgasmic, and coital imperatives that all render sex compulsory. Like much of the discourse concerning the black pill theory, these often-lurid expressions of biological determinism align incel masculinity with the hegemonic ideals that the forum participants wish to call into question. While incel forums angrily lament the grotesque behaviors of socalled Chads, users appear to be resigned to an inexorable sexual hierarchy that is more natural than cultural. Moreover, the participants highlighted above express frustration that they are not permitted to engage in these vulgar sexual practices. And though they indict dominant forms of masculinity tied to sexual prowess, strength, and physicality, they also engage in the demeaning sex talk and violent sexual fantasies that are part and parcel of contemporary rape culture.

As Anastasia Salter and Bridget Blodgett (2017) argue, geek, gamer, and online cultures are as much structured around the norms of hypermasculinity as conventional masculine spaces. Indeed, it is the ability of geek masculinity to present itself as victimized or marginal that enables online subcultures to disavow their contribution to the very masculine norms they decry. There is an ambivalence permeating 
incel hatred toward Chads. On the one hand, Chads are deplorable because they unfairly monopolize sex. On the other hand, incel fantasies would have them engage in the same behaviors-sometimes under the auspices of being nice guys.

Consider a radically different case of ambivalence, where users engage in thought experiments on how to eliminate sexual desire altogether. Some incel forum users go so far as to debate whether or not they should seek chemical or surgical castration so they are no longer pained by their unrequited sexual desire (Pindicked 2019). The more pessimistic among them suggest that the biological imperative is simply too strong. For instance, lordoftheincels comments, "I bet even if I was castrated I would still be so thirsty for her beautiful, perfectly round tits. This society is a complete dystopia for me. I hate this society" (2019a). In these forums, masculine desire is inescapable and painful for those who are unable to act on their urges. Whether one wishes to emulate alpha male behavior by ascending the sexual hierarchy or to annihilate their sexual urges altogether, nature is inescapable.

Here, the interplay of abject masculinity and compulsory sexuality also works to the exclusion of other forms of relational intimacy while exalting sex as the innermost expression of self. As Przybylo explains, compulsory sexuality explains "the social expectation that sexuality is a universal norm, that everyone should be sexual or desire sex, and that to not be sexual or desire sex is inherently wrong and in need of fixing" $(2016,182)$. A few posts from incels.net are particularly instructive. While most participants on incel forums express desire for deep meaningful connections and romantic relationships, sex and sexual attraction remain central preoccupations. To this effect, lordoftheincel's lamentation is worth quoting at length:

Whats wrong with sex? If an incel has had their heart broken dozens of times, and rejected dozens of times, why are they expected to prioritize personality first, sex second? Sex should come first. No sense in being friendzoned, investing a lot of time and energy, and having heart broken again. If incels are emotionally detached at the beginning, this is only natural after what they've been through. Sex should come first, then maybe after, once a woman demonstrates attraction, incel can form a proper emotional bond. Males are too cucked to see the double standard. And most of the people who say "sex is bad" are gigahypocrits who do onenight stands and have the most shallow sexual standards (2019b). 
This passage illustrates several common themes repeated across incel forums. First, it advances the notion that male-female relationships are exploitative of the male sex drive. By friendzoned, the user means that women craft disingenuous friendships with men whom they are not sexually attracted to in order to build their own egos and take advantage of their gullibility. Second, emotional attachment to women therefore represents a form of emasculation-which other users refer to elsewhere in various threads as being cucked (or cuckolded) by so-called alpha males who have sex with the women incels pursue. By this reading, the only relationship in a man's self-interest is a transactional one in which sex is exchanged for emotional attachment. Romantic or emotional relationships must be predicated on sex.

\section{Twisted Masculinity: Reading Elliot Rodger's Manifesto}

In this final section, we take a look at the most widely circulated text that has come to convey the violent ethos of incels, the online manifesto of Elliot Rodger. Rodger has become an emissary of incel masculinity. In the now-banned subreddit $\mathrm{r}$ /incel, users circulated memes of Rodger's face pasted over images of canonized Christian saints (Branson-Pott and Winton 2018). On the message board 4chan, some users declared May 23-the date of Rodger's violent rampage-a national holiday (Edwards 2018). Throughout the more lurid spaces of networked media, particularly men's rights portals, some continue to hail Rodger as a self-anointed supreme gentleman and applaud his day of retribution as heroic. Others on incel forums justify and praise his actions. In response to Rodger's attack, one user wrote the following on love-shy.com:

What happened is punishment for evil and violence of feminists and liberals. Any of you supporting atrocities like women's suffrage, immodest clothing, child support/alimony, no ban on adultery, ban on prostitution and a lack of female premarital chastity, all the things that drove this young man to be unable to find a girlfriend, are disgusting, horrible people and you created a culture where this is possible (Icepickthegod 2019). 
On Reddit, some users have praised Rodger's manifesto as a "good read" and "a Greek tragedy for the twenty-first century" that proved that "all women look for in a man in his face, is he hot or not" (ClarkFlory 2014). Of course, the smirking, quasi-ironic worship of Rodger makes it difficult to discern genuine appreciation of a mass murderer from taboo transgressions posted just for laughs. Although many incels reject Rodger and resent being associated with him, his mass shooting brought the incel subculture into the mainstream. Rodger never selfidentified as an incel, but he did frequent many of the sites incels have tended to visit, including love-shy.com, PUAhate.com, and the miscellaneous section of bodybuilding.com. Moreover, his 100,000-word online manifesto "My Twisted World" reflects the apocalyptic fantasies expressed by the more violent misogynists who populate incel forums.

The more violent and taboo threads of incel discourse embody a reactionary and repressive assault on the sexusociety, however minor. But even as they advocate a return to oppressive sex and gender roles, some incels demand the kind of sexual availability from young women that might be found in Playboy's version of the sexual revolution (Pitzulo 2011). Echoing a commonly expressed idea in incel forums, one incels.net user puts it, "The solution is goverment mandated gf [girlfriends] its that simple really" (Schizophrenic 2019). Put differently, this ambivalent desire for the return to a more female-repressive society is ultimately a desire for one that is more sexually liberated for men.

For the more violent and authoritarian-minded, such as Rodger, incel masculinity is consummated through fantasies of complete selfmastery of desire aided by the total subjugation of women and the enforcement of racial hierarchies. Here, we turn briefly to Rodger's manifesto to illustrate how incels appropriate and weaponize asexuality as an instrument of white male entitlement. It is important to note that although Rodger's ancestry is both Asian and white, he strongly identified as white and his manifesto is riddled with racism and antiBlackness. In his tedious recounting of every sexual rejection or unrequited desire he experience throughout his life, Rodger's manifesto is a tortured and poisonous manifest of victimhood, racism, and violent misogyny. The manifesto exemplifies how the confluence of racism, whiteness, and compulsory sexuality helped constitute the masculine politics of the alt-right. 
To this end, Rodger expressed an entitlement to sex that was grounded on his belief in the innate racial superiority of white males. In one particularly illustrative passage, he asserts:

\begin{abstract}
How could an inferior, ugly black boy be able to get a white girl and not me? I am beautiful, and I am half white myself. I am descended from British aristocracy. He is descended from slaves. I deserve it more. I tried not to believe his foul words, but they were already said, and it was hard to erase from my mind. If this is actually true, if this ugly black filth was able to have sex with a blonde white girl at the age of thirteen while I've had to suffer virginity all my life, then this just proves how ridiculous the female gender is. They would give themselves to this filthy scum, but they reject ME? The injustice! (Rodger 2014, 84).
\end{abstract}

Throughout his screed, Rodger took particular offense when he perceived that Black men and men of color were allowed to partake in privileges he has been denied. Here, Rodger invoked the trope of Black masculine hypersexuality that is the inheritance of anti-miscegenation and lynching discourses. Historically, the sexual violation of white womanhood-an icon of asexuality-as-ideal-has served as a rationale for the murder and violent subjugation of Black men (Owen 2014). This and similar passages in Rodger's manifesto evince how asexuality is misappropriated in rhetorics of whiteness to control both Black men's and white women's sexuality. Although Rodger concluded that he wished to eradicate sexual desire altogether, such statements illustrate how whiteness is exempt from its own edicts on sexual morality. That is to say that asexuality is reserved only for those who threaten whiteness. Here, the figure of the enjoying other that is so central to fascist rhetoric surfaces as an illusory barrier to white supremacy and fulfillment. Compulsory sexuality, then, demands that barriers to white enjoyment be violently eradicated.

Rodger's deployment of asexuality returns as a valorization of white masculine self-mastery and control. Put another way, Rodger's manifesto presents asexuality as a demonstration of white masculine restraint and superior morality. Its epilogue concludes that sex and sexual desire must be abolished for the sake of civilization's progress. Rodger imagined a dystopian world in which women would be enslaved for the sole purpose of procreation. In one passage, Rodger wrote: 
In fully realizing these truths about the world, I have created the ultimate and perfect ideology of how a fair and pure world would work. In an ideal world, sexuality would not exist. It must be outlawed. In a world without sex, humanity will be pure and civilized. Men will grow up healthily, without having to worry about such a barbaric act. All men will grow up fair and equal, because no man will be able to experience the pleasures of sex while others are denied it. The human race will evolve to an entirely new level of civilization, completely devoid of all the impurity and degeneracy that exists today (135).

Rodger's sadistic fantasies are cut from the cloth of eugenics, racism, fascism, and violent misogyny. But even within such blatant expressions of masculine violence, there are nonetheless subtleties. His comments illustrate how the more violent strands of incel discourse appropriate asexuality as a repressive disposition rather than a sexual orientation or withdrawal from the sexusociety. And though Rodger's fantasized total violent repression of the drives is the antithesis of the sexusociety, his discursive incitements ultimately stabilize sexuality by sketching the boundaries of sexual abnormality, inciting normal and healthy repetitions as the counterpoint to the incel. Note how his warped fantasy of asexuality is that it should be employed as a demonstration of power, intellectual supremacy, and white civilizational progress. With its references to impurity and degeneracy, his words evoke the sway of eugenic thought in the far-right's rhetoric of white victimhood: Personal pain and frustration are in fact a form of intentional political suffering brought about by the failure of liberal society to mirror nature. Fascism promises to purify society and restore white men to their position atop race and gender hierarchies.

Drawing from Foucault, Przybylo notes that one of the paradoxes of asexuality is that its representation and articulation constitutes not a threat but instead the very mechanism by which sexuality is resuscitated, "calling for future articulations of sexuality and exfoliating sexusociety" (2014, 452). Where incels fantasize about a de facto asexuality, enforced by violence, they ironically stabilize sexuality by inciting a "new discourse of sexuality, coercing us into a defence of sexuality; we become sexuality's defendants against the potential threat of asexuality" (452). Oftentimes, that which threatens sexuality with prohibition or censorship functions to "bring out the "will to knowledge' that serves as both their support and their instrument" (Foucault 1978, 12). Conversely, liberation proliferates sexual discourse so 
as to render sex open to new regimes of truth, knowledge, and power. The irony, therefore, of Rodger's violent and repressive deployment of asexuality is that it incessantly cites, recites, and incites the very sexual pleasures he claimed to abhor. There is a tension in the manifesto between Rodger's belief in his entitlement to sexually available women and his desire to eradicate sexuality in the name of selfmastery and control. Rather than challenge compulsory sexuality, the manifesto merely demands the return of white male dominance over sexual knowledge and practice. Indeed, unreflexive response to incels has largely been to defend compulsory sexuality. As journalists such as Jessa Crispin (2020) and Arwa Mahdawi (2020) have observed, both incredulous and sympathetic responses to incels have foregrounded the need for therapeutic responses that might bring incels back into the fold of normative sexuality. Put another way, public discourse by and about incels attends to their failure to live up to hegemonic masculinity rather than attempting to understand incels and fascist masculinity as a by-product of compulsory sexuality.

\section{Reclaiming Asexuality}

In this essay, we have turned to theories of asexuality to understand how incels distort their exile from the sexusociety into the very mechanisms that underwrite compulsory sexuality. We have observed how incels enact an abject form of white masculinity that in its failure to conform to the hegemonic conventions ultimately shores up a more diffuse and violent masculinist discourse. Compulsory sexuality and the male sex drive discourse are vital underlying principles of the fascist play of the alt-right. We are motivated by a series of troubling paradoxes or fundamental tensions present in contemporary incel discourse that illustrate how the so-called abnormalities embodied by sexual outliers and exiled subjects can in fact reaffirm the basic tenets of the sexual imperative and secure the borders of sex, sexuality, and masculinity. In our case studies, we have shown how the appropriation of incel terminology by sexually frustrated men has incited a seemingly endless flow of pained sexual discourse-much of which accedes to the cultural mythologies of sex drives that leave no space for identity or personal fulfillment absent sex and sexuality. Yet it is 
the discomforting expression of both pain and sex that incels require for them to maintain their communal bonds and, for lack of a better word, enjoy their subjectivity as sexless subjects. Although incels live out alternative relational intimacies, their discourse warps queer and asexual dispositions toward intimacy by redefining nonsexual erotics as biological impossibilities.

Despite the term's association with violent misogyny, incel discourse did begin as an attempt to reconcile and perhaps even recover asexuality from the underlying compulsory sexuality of both heterosexual and normative queer cultures. Incel was subsequently coopted as a moniker for misogynists who sought to understand their sexual alienation as the by-product not only of cultural forces such as feminism and liberalism but also natural forces such as genetics and instincts. They seem to blame nearly everything except compulsory sexuality for their woes. Incel's original yet severed connection with asexuality has become distanced from incisive critiques of the sexusociety and hetero/homonormativity and converted into a grotesque reaffirmation of the sexual and biological imperative. Yet we have also found a perverse queerness in incel identity in the sense that their shared intimacy and bonding over sexual failure and hatred of women mirrors fascist discourse of male autarky-a fantasy of a homosocial polity in which men are invulnerable and superior to women.

The implications of our analysis speak to both how the sexual imperative replicates itself through constant recitation-even among those dissident communities that refuse or otherwise misfire in their assimilation into compulsory sexuality. The dystopian queer worldun/making we have examined herein explains how incel culture nests within a broader and violent fascist politics that has germinated through men's rights networks and alt-right organizations. Incel discourse is a microcosm of a larger narrative about white male victimhood that is part and parcel of the politics of the Trump era. Some incels seize the mantle of victimhood to justify the violent oppression of women and people of color. Some even cruise the perverse literature of eugenicists, social Darwinists, white supremacists, ethnonationalists, fascists, and even jihadists to seek out a political ideology that will affirm their violent impulses and make them whole again. The quasi-ironic worship of violent misogynists and mass murderers throughout incel networks reflects a transgressive and reactionary 
political rhetoric meant to menace and terrorize liberal democracyall delivered with a subversive and disavowing smirk.

Although incel could be something other than what it has become, the violence it has engendered is no coincidence. Indeed, fascist rhetoric also touts male supremacy, violence, domination, militarism, and the subjugation of women's sexual freedom. It is no surprise, then, that incels comprise one of many nodes of online men's rights discourses that radicalizes young men and prepares them for violence. One challenge in responding to this violence, however, is that many fall into the trap of prescribing sex as the antidote. As we noted earlier, compulsory sexuality is what contributes to the alienating process where different forms of intimacy are eliminated or become supplanted by sex. It is not the lack of sex but instead the pressure to organize one's identity around sex that explains how and why young men come to see themselves as inexorably worthless. This explains why men become vulnerable to totalizing explanations of their suffering that map neatly onto fascist principles. Rather than seek the adjustment of incels to the sexusociety, our conclusion is that incel discourse might point us to queer and asexual futures in which fascism is as unthinkable as the impulse to reduce all social relationships to sexual transactions.

We believe that incel might be reimagined to critique compulsory sexuality and heteronormativity. Following Lee Edelman (2004), we maintain that refusing reproductive heterosexuality can be a source for a queer politic as opposed to the fascism of aggrieved entitlement. Edelman argues that conservative anxieties that same-sex love, fornication, and openness will spark the downfall of society are in some ways correct, since performing in the world without the telos of reproduction can create inventive disorientations. In addition to advocating for equal access to the status quo, queer politics thrives by "saying explicitly what ... they [conservatives] hear anyway in each and every expression or manifestation of queer sexuality: Fuck the social order and the Child in whose name we're collectively terrorized. ..." (Edelman 2004, 29). Most incels do not affirm this politics due to the force of compulsory sexuality. However, the current juncture and discourse of incels could have been formed otherwise, as evidenced in Alana and others' feminist coalition-building and care. Both camps do not make the jump, though, to critiquing the system of compulsory 
sexuality and stepping into the queer potentialities of a nonsexual, asexual, and non-natal positionality. Despite the fact that we have not seen these asexual potentialities activated, this future still holds possibility in its differential dormancy.

Caught between the pressures of compulsory sexuality and their own fascistic, pro-natalist discourse, incels create and suffer within a queer liminality-a product of failure that simultaneously exemplifies the flimsiness of their evolutionary ontology while affirming the very real psychosocial effects of not meeting the status quo. We argue that this pain-of biology, of masculinity, of procreation-is key to the constitutive process of both creating these fantasies and unmaking particular futures. We define this as a practice of queer world-un/ making, an attunement to how modalities of affective, rhetorical, futurity, and political identity production all paradoxically orient people toward openness to new intimacies while fostering destructive intimacy in the necessary closing of other possibilities. Lauren Berlant and Michael Warner argue that queer "world-making, as much in the mode of dirty talk as of print-mediated representation, is dispersed through incommensurate registers, by definition unrealizable as community or identity" $(1998,558)$, because worlds include persons who have not yet arrived and spaces not yet instantiated. In contrast, Elaine Scarry describes unmaking as essential to the constitution of pain. Thinking with the experience of torture, Scarry explains that "world unmaking, this uncreating of the created world, which is an external objectification of the psychic experience of the person in pain, becomes itself the cause of the pain" $(1987,45)$. We have evidenced a similar movement at play in constituting incel personas and discourses. The pressure of compulsory sexuality does not foreclose the production of homosociality. Incels do not suffer from a lack of intimacy, at least with other men. In this way, queer world-un/making foregrounds how incels need women to refuse them sex (which is not a difficult task considering their misogyny) to continue the excessive pleasures of being incel in the first place. To have sex is to obliterate their own nonnormative, dare we even say queer, sexual identities, yet incels revel in their identities of being sexless.

Incel masculinity forges a dystopian form of homosocial worldmaking that warps and bends asexuality into a call to arms. Reading Berlant and Warner against their grain, what is possible when 
we approach a queer world as "a space of entrances, exits, unsystematized lines of acquaintance, projected horizons, typifying examples, alternate routes, blockages, [and] incommensurate geographies" that just as much destroys potentialities as it constitutes (Jagose 2000)? The split between feminist incel potentialities and the dominant, fascistic homosociality of incel discourse articulates how "much our most intimate experience and self-understanding relies on a world that is essentially public, and brought into being by the interactivity of others" in a way different than it seems Warner (quoted in Jagose [2000]) intended, unearthing an underbelly present in every moment of constitution. Troubling the tendency for queer world-making to mark identity construction only positively, queer world-un/making is an initial invitation to consider how asexuality challenges the sedimenting assumptions about what can be queer, sexual, political, and generative.

Casey Ryan Kelly is a professor of rhetoric and public culture at the University of Nebraska-Lincoln. He has authored three books, including Apocalypse Man: The Death Drive and the Rhetoric of White Masculine Victimhood.

Chase Aunspach is an instructor of speech communication at the University of South Carolina-Sumter and a doctoral candidate in the Department of Communication Studies at the University of Nebraska-Lincoln. His research dwells rhetorically at the intersection of technologies, queerness, masculinities, and posthumanisms. Chase's current work spelunks in masculine communities on Reddit to illuminate how gendered forms structure contemporary reactionary politics and disinformation in the United States.

\section{References}

Alana. 1999. “Involuntary Celibacy Mailing List.” October 12, 1999. https:// web.archive.org/web/19991012051322/http://www.ncf.carleton.ca/ adog7/ mailing-list.htm

Alana. 1997a. “Alana’s Involuntary Celibacy Project.” February 29, 1997. https:// web.archive.org/web/20000229132824/http://www.ncf.carleton.ca/ adog7/ ic-home.html

Alana. 1997b. “Other People Stories.” August 1, 1997. https://web.archive.org/ web/19970801152220/http://www.ncf.carleton.ca/ adog7/response.html Apatow, Judd. 2005. The 40-Year-Old Virgin. DVD. Universal City, CA: Universal Pictures. 
Banet-Weiser, Sarah and Kate M. Miltner. 2016. "\#MasculinitySoFragile: Culture, Structure, and Networked Misogyny." Feminist Media Studies 16, no. 1 (January): 171-74.

BBC, “Toronto Van Attack Suspect Praised 'Incel' Killer," 2018. BBC News, April 25, 2018. http://www.bbc.com/news/world-us-canada-43883052

Bederman, Gail. 2008. Manliness and Civilization: A Cultural History of Gender and Race in the United States, 1880-1917. Chicago: University of Chicago Press.

Bellassai, Sandro. 2005. "The Masculine Mystique: Antimodernism and Virility in Fascist Italy." Journal of Modern Italian Studies 10, no. 3 (September): 314-35.

Berger, Maurice, Brian Wallis, and Simon Watson, eds. 1995. Constructing Masculinity. New York: Routledge.

Berlant, Lauren and Michael Warner. 1998. "Sex in Public." Critical Inquiry 24, no. 2 (Winter): 547-66.

Bever, Lindsey. 2019. "A Man Cited His Virginity as Reason He Planned to Kill 'as Many Girls' as He Could, Police Say.” Washington Post, January 22, 2019. https://www.washingtonpost.com/crime-law/2019/01/22/man-cited-hisvirginity-reason-he-planned-kill-many-girls-he-could-police-say/?utm term $=.231 \mathrm{cdb} 6647 \mathrm{fo}$

blickpall. 2018. "Evolutionary Psychology and Mate Selection in the Age of Tinder." Incels.co (online forum), April 28, 2018. https://web.archive.org/save/https://incels.co/threads/ evolutionary-psychology-and-mate-selection-in-the-age-of-tinder.39777

Branson-Potts, Hailey and Richard Winton. 2018. "How Elliot Rodger Went from Misfit Mass Murderer to 'Saint' for Group of Misogynists-and Suspected Toronto Killer." Los Angeles Times, April 26, 2018. https://www.latimes.com/ local/lanow/la-me-ln-elliot-rodger-incel-20180426-story.html

Bratich, Jack and Sarah Banet-Weiser. 2019. "From Pick-Up Artists to Incels: Con(fidence) Games, Networked Misogyny, and the Failure of Neoliberalism," International Journal of Communication 13 (January): 5003-27.

Carroll, Hamilton. 2011. Affirmative Reaction: New Formations of White Masculinity. Durham, NC: Duke University Press.

Clark-Flory, Tracy. 2014. "Inside the Terrifying, Twisted Online World of Involuntary Celibates." Salon, May 28, 2014. https://www.salon.com/2014/05/27/ inside the terrifying twisted online world of involuntary celibates

Collins, Ben and Brandy Zadrozny. 2018. "After Toronto Attack, Online Misogynists Praise Suspect as 'New Saint.' ” NBC News, April 25, 2018. https://www.nbcnews.com/news/us-news/ after-toronto-attack-online-misogynists-praise-suspect-new-saint-n868821

Connell, R. W. 2005. Masculinities. 2nd edition. New York: Polity.

Cornell Law School. n.d. "45 CFR § 46.102-Definitions for purposes of this policy.” Legal Information Institute, Ithaca, NY. https://www.law.cornell.edu/ cfr/text/45/46.102 
Crispin, Jessa. 2020. “ 'Incel' Culture Has Sparked Panic and Pity-but Little Thoughtful Conversation." Guardian, May 1, 2020. http://www.theguardian. com/commentisfree/2020/may/01/incel-culture-film-tfw-no-gf-jessa-crispin

DisabledFace. 2019. "What Do You Guys Think of MGTOW?” Incels.net (online forum), August 9, 2019. https://web.archive.org/web/20190814204243/ https://incels.net/threads/what-do-you-guys-think-of-mgtow.2988/page-2

Eco, Umberto. 1995. “Ur-fascism.” New York Review of Books, June 22, 1995.

Edelman, Lee. 2004. No Future: Queer Theory and the Death Drive. Durham, NC: Duke University Press.

Edwards, Stassa. 2018. "Saint Elliot Rodger and the 'Incels' Who Canonize Him.” Jezebel (website). April 27, 2018. https://jezebel.com/ saint-elliot-rodger-and-the-incels-who-canonize-him-1825567815

Foucault, Michel. 1978. The History of Sexuality. Vol. I: An Introduction. Translated by Robert Hurley. New York: Vintage Books.

franzke, aline shakti, Anja Bechmann, Michael Zimmer, and Charles M. Ess. 2020. "Internet Research: Ethical Guidelines 3.o." Association of Internet Researchers. https://aoir.org/reports/ethics3.pdf

Futrelle, David. 2017. "Men's-Rights Activism Is the Gateway Drug for the Alt-Right.” New York Magazine, August 17, 2017. https://www.thecut. $\mathrm{com} / 2017 / 08 / \mathrm{mens}$-rights -activism-is-the-gateway-drug-for-the-alt-right. html.

Gardiner, Judith Kegan. 2013. Masculinity Studies and Feminist Theory: New Directions. New York: Columbia University Press.

Ging, Debbie. 2019. "Alphas, Betas, and Incels: Theorizing the Masculinities of the Manosphere." Men and Masculinities 22, no. 4 (October): 638-57.

Gupta, Kristina. 2015. "Compulsory Sexuality: Evaluating an Emerging Concept.” Signs: Journal of Women in Culture and Society 41, no. 1 (Autumn): 131-54.

Halberstam, Jack. 2005. In a Queer Time and Place: Transgender Bodies, Subcultural Lives. New York: New York University Press.

Hardwick, Catherine. 2008. Twilight. DVD. Santa Monica, CA: Summit Entertainment.

Hollway, Wendy. 1998. "Gender Difference and the Production of Subjectivity." In Changing the Subject: Psychology, Social Regulation and Subjectivity, edited by Julian Henriques, Wendy Hollway, Cathy Urwin, Couze Venn, and Valerie Walkerdine, 2nd edition, 227-63. New York: Routledge.

Icepickthegod. 2019. "Elliot Rodgers Manifesto: My Twisted World Is a Good Read.” Reddit. https://web.archive.org/web/20190820004727/ https://www.reddit.com/r/unpopularopinion/comments/6ytt1m/ elliot rodgers manifesto my twisted world is a

Jagose, Annamarie. 200o. "Queer World Making: Annamarie Jagose Interviews Michael Warner.” Genders, May 1, 2000. https:// www.colorado.edu/gendersarchive1998-2013/2000/05/01/ queer-world-making-annamarie-jagose-interviews-michael-warne 
Jaki, Sylvia, Tom De Smedt, Maja Gwóźdź, Rudresh Panchal, Alexander Rossa, and Guy De Pauw. 2019. "Online Hatred of Women in the Incels.Me Forum: Linguistic Analysis and Automatic Detection.” Journal of Language Aggression and Conflict 7, no. 2 (November): 240-68.

Johnson, Paul Elliott. 2017. "The Art of Masculine Victimhood: Donald Trump's Demagoguery." Women's Studies in Communication 40, no. 3 (August): 229-50.

Kelly, Casey Ryan 2016. Abstinence Cinema: Virginity and the Rhetoric of Sexual Purity in Contemporary Film. New Brunswick, NJ: Rutgers University Press.

- 2018. "The Wounded Man: Foxcatcher and the Incoherence of White Masculine Victimhood." Communication and Critical/Cultural Studies 15, no. 2 (April): 161-8.

-2020. Apocalypse Man: The Death Drive and the Rhetoric of White Masculine Victimhood. Columbus: Ohio State University Press

Khan, Imran. 2010. “The Misandry Bubble.” The Futurist, January 1, 2010. https://web.archive.org/web/20190817232739/https://www.singularity2050. com/2010/01/the-misandry-bubble.html

Kimmel, Michael S. 2012. Manhood in America: A Cultural History. New York: Oxford University Press.

- 2015. Angry White Men: American Masculinity at the End of an Era. New York: Nation Books.

King, Claire Sisco. 2009. "It Cuts Both Ways: Fight Club, Masculinity, and Abject Hegemony." Communication and Critical/Cultural Studies 6, no. 4 (December): 366-85.

- 2011. Washed in Blood: Male Sacrifice, Trauma, and the Cinema. New Brunswick, NJ: Rutgers University Press.

Lorde, Audre. 1984. "Uses of the Erotic: The Erotic as Power." In Sister Outsider: Essays and Speeches, 53-59. Berkeley, CA: Crossing Press.

lordoftheincels. 2019a. "Feminist Lands (My Poor Penis)." Incels.net (online forum), May 10, 2019. https://web.archive.org/web/20190814203807/https:// incels.net/threads/femini\%D1\%95t-lands-my-poor-penis.1068

lordoftheincels. 2019b. "What's Wrong With Sex?" Incels.net (online forum), August 14, 2019. https://web.archive.org/web/20190814203847/https://incels. net/threads / whats-wrong-with-sex.3087

Mahdawi, Arwa. 2020. "Why Do We Only Care About Incels When They Are Men?” Guardian, February 19, 2020. http://www.theguardian.com/ commentisfree/2020/feb/19/why-only-care-incels-men-involuntary-celibacy

Marcuse, Herbert. 1974. Eros and Civilization : A Philosophical Inquiry into Freud. Boston: Beacon Press.

McGowan, Todd. 2013. Enjoying What We Don't Have: The Political Project of Psychoanalysis. Lincoln: University of Nebraska Press.

Nagle, Angela. 2017. Kill All Normies: Online Culture Wars From 4Chan And Tumblr To Trump And The Alt-Right. Washington, DC: Zero Books. 
Nicolson, Paula. 1993. "Public Values and Private Beliefs: Why Do Women Refer Themselves to Sex Therapy?” In Psychological Perspectives on Sexual Problems: New Directions in Theory and Practice, edited by Jane M. Ussher and Christine D. Baker, 56-78. London: Routledge.

Owen, Ianna Hawkins. 2014. "On the Racialization of Asexuality." In Asexualities: Feminist and Queer Perspectives, edited by KJ Cerankowski and Megan Milks, 119-35. New York: Routledge.

—. 2018. "Still, Nothing: Mammy and Black Asexual Possibility." Feminist Review 120, no. 1 (November): 70-84.

Pitzulo, Carrie. 2011. Bachelors and Bunnies: The Sexual Politics of Playboy. Chicago: University of Chicago Press.

Potts, Annie. 2016. "Coming, Coming, Gone: A Feminist Deconstruction of Heterosexual Orgasm.” Sexualities 3, no. 1 (February): 55-76.

Pindicked. 2019. “If There's No Hope, Why Not Get Castrated?” Incels.net (online forum), July 3, 2019. https://web.archive.org/web/20190814203713/https:// incels.net/threads/if-theres-no-hope-why-not-get-castrated.1792

Przybylo, Ela. 2011. "Crisis and Safety: The Asexual in Sexusociety." Sexualities 14, no. 4 (August): 444-61.

— 2014. "Masculine Doubt and Sexual Wonder Asexually-Identified Men Talk About Their (A)Sexualities." In Asexualities: Feminist and Queer Perspectives, edited by KJ Cerankowski and Megan Milks, 225-46. New York: Routledge.

- 2016. "Introducing Asexuality, Unthinking Sex." In Introducing the New Sexuality Studies, 3rd edition, edited by Nancy L. Fischer and Steve Seidman, 181-91. New York: Routledge.

- 2019. Asexual Erotics: Intimate Readings of Compulsory Sexuality. Columbus: Ohio State University Press.

Reich, Wilhelm. (1933) 1980. The Mass Psychology of Fascism. Translated by Vincent R. Carfagno. New York: Farrar, Straus and Giroux.

Retrycon. 2019. "Are Incels All About Sex or [do] They Want Love?" Incels.net (online forum), July 8, 2019. https://web.archive.org/web/20190814204143/ https://incels.net/threads/are-incels-all-about-sex-or-they-want-love.1963

Robinson, Sally. 200o. Marked Men: White Masculinity in Crisis. New York: Columbia University Press.

Rodger, Elliot. 2014. "My Twisted World: The Story of Elliot Rodger." May 22, 2014. https://www.documentcloud.org/documents/1173808-elliot-rodgermanifesto.html

Rubin, Gayle. 1975. “The Traffic in Women: Notes on the 'Political Economy' of Sex." In Toward an Anthropology of Women, edited by Rayna R. Reiter, 157-210. New York: Monthly Review Press.

Saint Escortcel. 2019. "Are Incels All About Sex or [Do] They Want Love?” Incels.net (online forum), July 8, 2019. https://incels.net/threads/ are-incels-all-about-sex-or-they-want-love.1963/page-2

Salter, Anastasia and Bridget Blodgett. 2017. Toxic Geek Masculinity in Media: Sexism, Trolling, and Identity Policing. New York: Palgrave Macmillan. 
Scarry, Elaine. 1987. The Body in Pain: The Making and Unmaking of the World. New York: Oxford University Press.

Scherrer, Kristin S. 2008. "Coming to an Asexual Identity: Negotiating Identity, Negotiating Desire.” Sexualities 11, no. 5 (October): 621-41.

Schizophrenic. 2019. "Let's Talk Solutions." Incels.net (online forum), July 19, 2019. https://incels.net/threads/ let $\%$ E2\%80\%9gs-talk-solutions.2332/\#post-32487

"Scientific Blackpill." n.d. Incel Wiki (website). Last modified August 14, 2019. https://web.archive.org/web/20190814204111/https://incels.wiki/w/ Scientific Blackpill

Seidman, Steven. 1992. Embattled Eros: Sexual Politics and Ethics in Contemporary America. 1st edition. New York: Routledge.

Siklic, Marjan. 2013a. "Programs for Treating Incel/Love-Shyness." governmentsgetgirlfriends (blog), February 11, 2013. https://web.archive. org/web/20130211225900/http://governmentsgetgirlfriends.wordpress. com/867-2

—. 2013b. "My Parents-Criminals Who Deserve to Be Put in Jail or Killed." governmentsgetgirlfriends (blog), February 1, 2013. https://web.archive. org/web/20130211020846/http://governmentsgetgirlfriends.wordpress. com/2013/02/01/my-parents-criminals-who-deserve-to-be-put-in-jail-or-killed

Solon, Olivia. 2017. “ 'Incel': Reddit Bans Misogynist Men’s Group Blaming Women for Their Celibacy.” Guardian, November 8, 2017. http://www.theguardian. com/technology/2017/nov/08/reddit-incel-involuntary-celibate-men-ban

Sontag, Susan. 2002. Under the Sign of Saturn: Essays. 1st edition. New York: Picador.

Spackman, Barbara. 1996. Fascist Virilities: Rhetoric, Ideology, and Social Fantasy in Italy. Minneapolis: University of Minnesota Press.

umbasa. 2018. "Concern for the Rise of Incel." Asexual Visibility and Education Network (online forum), June 9, 2018. https://web.archive.org/save/https:// www.asexuality.org/en/topic/172380-concern-for-the-rise-of-incel

Vogt, PJ 2018. \#120Invcel. Reply All (podcast), May 10, 2018. https://gimletmedia. com/shows/reply-all/76h59o/120-invcel

Woodley, Daniel. 2009. Fascism and Political Theory: Critical Perspectives on Fascist Ideology. New York: Routledge.

Woods, Heather Suzanne and Leslie A. Hahner. 2019. Make America Meme Again: The Rhetoric of the Alt-Right. New York: Peter Lang. 